\title{
Muscle weakness is related to utilization of health care resources in COPD patients
}

\author{
M. Decramer*, R. Gosselink*, T. Troosters*, M. Verschueren**, G. Evers**
}

Muscle weakness is related to utilization of health care resources in COPD patients M. Decramer, R. Gosselink, T. Troosters, M. Verschueren, G. Evers. (CERS Journals Ltd 1997.

ABSTRACT: The factors determining utilization of health care resources in patients with chronic obstructive pulmonary disease (COPD) are poorly understood. In order to obtain insight into these factors, we studied the utilization of health care resources in 57 stable COPD patients with a forced expiratory volume in one second (FEV1) of $36 \pm 9 \%$ predicted.

Patients were divided into two groups: admitted at least twice in the last year (high medical consumption; $\mathbf{n = 2 3}$ ) or not admitted in the last year (low medical consumption; $\mathbf{n = 3 4}$ ). Other variables related to utilization of health care resources studied were: the number of hospital days; the number of out-patient visits to a pulmonary department in the last year; and the average daily dose (ADD) of corticosteroids taken in the last 6 months. The actual cost of utilization of health care resources, however, was not studied. In addition, pulmonary function, serum electrolytes, blood gas values, 6 min walking distance, respiratory and peripheral muscle force, and appraisal of self-care agency (ASA score) were studied.

Pulmonary function, serum electrolytes, blood gas values, ASA score and walking distance were not different between the two groups (e.g. FEV1 $36 \pm 8$ vs $36 \pm 10 \%$ pred). Respiratory muscle forces tended to be lower in the high medical consumption group, this tendency almost reaching statistical significance for maximal expiratory pressure $(P \mathrm{E}, \max )(\mathrm{p}=\mathbf{0 . 0 8})$. Peripheral muscle force, however, was clearly reduced in the high medical consumption group (quadriceps force $63 \pm 20$ vs $\mathbf{8 2} \pm \mathbf{2 6} \%$ pred; $\mathrm{p}<\mathbf{0 . 0 5}$ ). The number of admissions, the number of hospital days, the number of out-patient visits, and ADD were interrelated and also related to ventilatory and peripheral muscle force $(\mathbf{r}-\mathbf{0 . 1 8}$ to $-\mathbf{0 . 3 8})$. This relationship was statistically significant for $P \mathrm{E}$,max, whilst a similar tendency was present for maximal inspiratory pressure $(P I, \max )$. In stepwise multiple regression analysis, only quadriceps force was a significant determinant of utilization of health care services.

We conclude that utilization of health care services in patients with chronic obstructive pulmonary disease is related to ventilatory and peripheral muscle force. Whether or not reduced muscle force is simply an expression of disease severity remains to be determined.

Eur Respir J 1997; 10: 417-423.

\begin{abstract}
*Respiratory Rehabilitation and Respiratory Division, University Hospitals and ** School of Public Health, Katholieke Universiteit, Leuven, Belgium.
\end{abstract}

Correspondence: M. Decramer

Respiratory Division

University Hospitals Herestraat 49

B-3000 Leuven

Belgium

Keywords: Chronic obstructive pulmonary disease

medical consumption

pulmonary function

respiratory muscles

utilization of health care resources

ventilatory and peripheral muscle

weakness

\section{Received: July 261995}

Accepted after revision October 241996

Supported by a grant from the "Nationaal Fonds voor Wetenschappelijk Onderzoek" and "Nationale Vereniging tot Steun aan Gehandicapte Personen".
Utilization of health care resources is, without question, important in patients with chronic obstructive pulmonary disease (COPD). In the USA, the cost of medical care for COPD was 4.55 billion dollars in 1972, 19 billion dollars in 1979, and 27 billion dollars in 1982 [1]. The factors determining medical consumption in these patients remain poorly understood. Although it is intuitively likely that utilization of health care resources is related to disease severity, to the best of our knowledge no direct evidence for such a relationship is present. In addition, one study suggested that drugs are frequently misused in COPD patients [2], and therefore health care services in general may also be misused.

It is generally claimed that pulmonary rehabilitation affects the utilization of health resources. Indeed, several studies have suggested that pulmonary rehabilitation programmes may reduce the use of health care resources [1]. None of these studies had a randomized controlled design, and the conclusions, therefore, remain preliminary. In addition, one study has suggested that an education programme may substantially reduce the utilization of health care resources by COPD patients [3], although other studies have suggested that education programmes only affect health-related knowledge without affecting health status, as such [4-6].

If better control of the utilization of health resources in COPD patients is required, then insight into the factors determining it is the first requirement necessary. The present study was, therefore, designed to examine the relationship between the utilization of health care resources and functional variables, and thus to examine whether functional variables are determinants of use of health 
care services in COPD patients. We observed a relationship between the utilization of health care resources and ventilatory and peripheral muscle weakness. Whether this relationship is a direct or causative one, or the result of an apparent relationship with disease severity needs to be further examined.

\section{Methods}

Fifty seven male patients with stable COPD, seen in our out-patient clinic over a 6 month period were admitted to the study. They all had a forced expiratory volume in one second (FEV1) ranging approximately $20-40 \%$ predicted. They were divided into a high and low use of health care resources group on the basis of the number of admissions in the last year. For simplicity, we will refer to the use of health care resources as medical consumption. They were admitted at least twice in the last year (high medical consumption; $n=23$ ), or were not admitted in the last year (low medical consumption; $\mathrm{n}=34$ ). Patients admitted only once in the last year were not studied. They underwent pulmonary function tests, tests of peripheral and ventilatory muscle function, a 6 min walking distance and a questionnaire used to construct an appraisal of self care agency score [7, 8].

\section{Utilization of health care resources}

Four variables related to the use of health care resources were used in the present study: the number of hospital admissions in the last year; the total number of days spent in hospital in the last year, obtained by adding all days in hospital during various admissions; the number of out-patient visits with a pulmonary specialist in the last year, and the average daily dose (ADD) of corticosteroids taken in the last 6 months. Twenty eight of the 57 patients were treated with systemic corticosteroids. Most of these patients were treated with repetitive bursts of steroid treatment at the time of exacerbations. All patients were treated with methylprednisolone. Of these 28 patients, six came from the low medical consumption group and 22 from the high medical consumption group. The ADD in the last 6 months was calculated by adding all doses of corticosteroids and dividing by the number of days in 6 months [9]. The total cost of health care was not analysed. All admissions were due to an exacerbation of respiratory disease and not to concomitant disease. Half of the exacerbations were due to documented infection, and the other half to enhanced bronchospasm. Infection was diagnosed on the basis of history of coloured sputum, leucocytosis, positive sputum stain on admission, or radiographic signs of infection.

\section{Pulmonary function tests}

All patients underwent spirometry, with determination of FEV1 and vital capacity (VC). Functional residual capacity (FRC) was measured with a constant volume plethysmograph (Medical Graphics Inc, ST. Paul, MN,
USA). Spirometry was performed using the pneumotachograph of this plethysmograph (Medical Graphics Inc.), according to American Thoracic Society (ATS) recommendations, using the tracing yielding the greatest sum of VC and FEV1 [10]. The values obtained were related to the normal values published by QUANJER et al. [11]. Transfer factor of the lungs for carbon monoxide $(T \mathrm{~L}, \mathrm{CO})$ was measured with the single-breath carbon monoxide diffusion method [12], and related to the normal values given by Cotes et al. [13]. Six minute walking distance was measured as the distance that could be run or walked in $6 \mathrm{~min}$. A standardized trail was used in a corridor. Each test was performed three times. Encouragement was standardized [14]. Dyspnoea at rest was measured using a visual analogue score (VAS) [15], while exercise dyspnoea was measured with a modified Borg score [16]. With the VAS, dyspnoea was expressed in $\mathrm{mm}$, ranging $0-10 \mathrm{~mm}$. With the Borg score, a number from 0 to 10 was obtained, corresponding to the severity of dyspnoea statement judged appropriate by the patient.

\section{Respiratory muscle force}

All patients underwent determination of maximal inspiratory pressure $(P \mathrm{I}, \max )$ and maximal expiratory pressure $(P \mathrm{E}, \max )$. These pressures were measured according to a modification of the method of BLACK and HYATT [17]. The modification consisted in the use of an electronic transducer instead of an aneroid manometer. PI,max was measured near residual volume (RV), while $P$ E, max was measured near total lung capacity (TLC). The values measured were related to the normal values of ROCHESTER and Arora [18].

\section{Serum electrolytes}

In 23 patients from the low medical consumption group and in 20 patients from the high medical consumption group, serum electrolytes were determined using an automated analysis system (Hitachi 911-4, Japan). The electrolytes included: sodium, potassium, chloride, calcium and phosphorus.

\section{Blood gas values}

In 19 patients from the high medical consumption group and in 12 patients from the low medical consumption group, blood gas values were determined using an automated Corning System (Corning Medical Instruments, Medfield, MA, USA). Three patients from the low medical consumption group and one patient from the high medical consumption group were on chronic oxygen therapy.

\section{Quadriceps force}

Quadriceps force (QF) was measured using a Cybex II dynamometer (Lumex Corp., Bay Shore, NY, USA). Peak torque was measured at the dominant side, during a maximal knee extension manoeuvre with the hip in 
$90^{\circ}$ flexion and the knee in $60^{\circ}$ flexion. Values obtained were related to normal values developed in our laboratory, by testing normal subjects. These normal values take age, gender and body weight into account. The prediction formula is QF (in Nm) $=-2.21 \times$ age $+55.9 \times$ gender $($ female $=0$, male $=1)+1.78 \times$ body weight +124 , with a residual standard deviation (RSD) of $37.1 \mathrm{Nm}$. Reproducibility was assessed by testing 10 normal subjects on two nonconsecutive days. Reproducibility was good, with a difference between test and retest of $8.6 \%$, and a repeatability coefficient of $43 \mathrm{Nm}$.

\section{Appraisal of self-care agency}

Self-care capacity was estimated using the appraisal of self-care agency (ASA) scale [7, 8]. The instrument used measures the capability of a patient to investigate his condition, to decide what action to take, and to perform technical procedures of self-care [19]. This includes active participation in treatment and decisions about medical consumption. A self-completed instrument was used in the present study. The Likert type scale had five response categories. They ranged from total disagreement to total agreement, with numbers increasing from one to five. The scores on 24 items were added into an unweighted total score. Theoretical range of scores is 24-120. High scores indicate more self-care capacity. Internal consistency of the Dutch translation of the scale ranges $0.75-0.80$. Test-retest reliability was 0.72 .

\section{Statistics}

Statistical analysis was performed on the data obtained in the two subsets of patients, using unpaired t-tests. A p-value less than $<0.05$ was considered to be statistically significant. Correlation coefficients among different functional variables, ASA score, and variables related to utilization of health care resources were calculated. For the variables related to utilization of health care resources, a stepwise multiple regression analysis was performed using medical consumption as a dependent variable. Variables used in the model included: FEV1, $P$ I,max, $P$ E,max, QF and ASA score. Only variables contributing significantly were retained in the final analysis.

\section{Results}

\section{Utilization of health care resources}

Data on utilization of health care resources are summarized in table 1 . Patients in the high medical consumption group had been admitted on average $2.3 \pm 0.5$ times in the last year, whereas patients in the low medical consumption group had not been admitted in the last year. The number of days spent in hospital was consequently clearly different ( $30 \pm 16$ vs 0 days). The number of out-patient visits was also different between the two groups $(4.4 \pm 2.4$ vs $2.7 \pm 1.5$ visits). The average daily dose of steroids taken in the last 6 months was
Table 1. - Variables related to utilization of health care resources

\begin{tabular}{lcc}
\hline & $\begin{array}{c}\text { High medical } \\
\text { consumption } \\
\text { group }\end{array}$ & $\begin{array}{c}\text { Low medical } \\
\text { consumption } \\
\text { group }\end{array}$ \\
\hline Patients n n & 23 & 34 \\
Admissions n & $2.3 \pm 0.5$ & 0 \\
Hospital days n & $30 \pm 16$ & 0 \\
Out-patient visits n & $4.4 \pm 2.4$ & $2.7 \pm 1.5$ \\
ADD mg & $4.6 \pm 3.2$ & $0.5 \pm 1.2$ \\
\hline
\end{tabular}

ADD: average daily dose of steroids taken in the last 6 months, expressed in methylprednisolone equivalents.

clearly greater in the high medical consumption group $\left(4.6 \pm 3.2 \mathrm{vs} 0.5 \pm 1.2 \mathrm{mg} \cdot \mathrm{day}^{-1}\right)$. It is of interest to note that the various measures of medical consumption were interrelated. The number of hospital days correlated with the number of admissions $(r=0.86 ; p<0.001)$, while the number of out-patient visits correlated both with the number of admissions $(\mathrm{r}=0.48 ; \mathrm{p}<0.001)$ and the number of hospital days $(r=0.32 ; p<0.05)$. ADD was related to all three other measures of medical consumption (r 0.28-0.69; $\mathrm{p}<0.05-<0.001$ ).

\section{Anthropometric and pulmonary function data}

Anthropometric and pulmonary function data of the patients are summarized in table 2. As can be seen, FEV1, TL,CO and FRC were not significantly different between the two groups. Although 6 min walking distance tended to be higher in the low medical consumption group, the difference was not statistically significant.

Table 2. - Anthropometric data, pulmonary function data and muscle forces

\begin{tabular}{lccc}
\hline & $\begin{array}{c}\text { High medical } \\
\text { consumption } \\
\text { group }\end{array}$ & $\begin{array}{c}\text { Low medical } \\
\text { consumption } \\
\text { group }\end{array}$ \\
\hline Age yrs & $63 \pm 9$ & $65 \pm 9$ \\
Height cm & $168 \pm 8$ & $172 \pm 7$ \\
Weight $\mathrm{kg}$ & $67 \pm 11$ & $69 \pm 12$ \\
BMI $\mathrm{kg} \cdot \mathrm{m}^{-2}$ & $24 \pm 4$ & $24 \pm 4$ \\
FEV1 L & $1.04 \pm 0.2$ & $1.08 \pm 0.4$ \\
& $\%$ pred & $36 \pm 8$ & $36 \pm 10$ \\
FRC $\%$ pred & $155 \pm 37$ & $171 \pm 34$ \\
TL,CO $\%$ pred & $63 \pm 21$ & $65 \pm 30$ \\
6MWD m & $358 \pm 123$ & $399 \pm 126$ \\
Dyspnoea score (Borg) & $4.6 \pm 1.5$ & $3.8 \pm 2.4$ \\
PI,max \% pred & $64 \pm 25$ & $73 \pm 25$ \\
PE,max $\%$ pred & $70 \pm 24$ & $84 \pm 31^{+}$ \\
QF $\%$ pred & $66 \pm 29$ & $83 \pm 25^{*}$ \\
ASA score & $85 \pm 10$ & $89 \pm 10$ \\
\hline
\end{tabular}

BMI: body mass index; FEV1: forced expiratory volume in one second; $\%$ pred: percentage of predicted value; FRC: functional residual capacity; $T \mathrm{~L}, \mathrm{CO}$ : transfer factor of the lungs for carbon monoxide; 6MWD: 6 min walking distance; $P \mathrm{I}$,max: maximal inspiratory pressure; $P$ E,max: maximal expiratory pressure; QF: quadriceps force; ASA: appraisal of self-care agency. *: $p<0.05{ }^{+}: \mathrm{p}<0.10$, compared to high medical consumption group. 
Table 3. - Relationship between utilization of health care resources and functional variables in single regression analysis

\begin{tabular}{lcccccc}
\hline & $\begin{array}{c}\text { FEV } \\
\%\end{array}$ & $\begin{array}{c}P \text { I,max } \\
\%\end{array}$ & $\begin{array}{c}P \text { E,max } \\
\%\end{array}$ & $\begin{array}{c}\text { QF } \\
\%\end{array}$ & $\begin{array}{c}6 \text { MWD } \\
\text { m }\end{array}$ & $\begin{array}{c}\text { ASA } \\
\text { score }\end{array}$ \\
\hline Admissions n & NS & NS & $-0.30^{*}$ & $-0.33^{*}$ & NS & NS \\
Hospital days n & NS & NS & $-0.26^{+}$ & $-0.36^{*}$ & NS & NS \\
Out-patient visits & NS & $-0.26^{+}$ & $-0.26^{+}$ & $-0.38^{*}$ & NS & NS \\
ADD score & NS & NS & NS & $-0.36^{*}$ & NS & NS \\
\hline
\end{tabular}

Regression values are presented. For definitions see legend to tables 1 and 2 . $^{*}: \mathrm{p}<0.05 ;{ }^{+}: \mathrm{p}=0.06$.

Dyspnoea score measured with the Borg score and the VAS was not significantly different between the two groups.

\section{Serum electrolytes and blood gas values}

Serum electrolytes were not significantly different between the two groups. Moreover, blood gas tensions were also similar between the two groups. Arterial oxygen tension $\left(P \mathrm{a}, \mathrm{O}_{2}\right)$ averaged $9.5 \pm 2.0 \mathrm{kPa}(71 \pm 15 \mathrm{mmHg})$ in the high medical consumption group, and $9.3 \pm 0.9 \mathrm{kPa}$ $(70 \pm 7 \mathrm{mmHg})$ in the low medical consumption group.

\section{Muscle forces}

Muscle forces are also summarized in table 2. As can been seen both for $P \mathrm{I}$,max and $P \mathrm{E}$,max, a tendency for a difference was present, almost reaching statistical significance for $P \mathrm{E}, \max (\mathrm{p}=0.08)$. A clear difference was present for $\mathrm{QF}$ between the two groups $(\mathrm{p}<0.05)$. PI,max and $P$ E,max were not significantly related to FEV 1 ( $\mathrm{r}=0.14$ and $\mathrm{r}=0.15$, respectively), while $P \mathrm{I}$,max was significantly related to $T \mathrm{~L}, \mathrm{CO}(\mathrm{r}=0.34 ; \mathrm{p}<0.05)$. QF was related to FEV1 $(r=0.33 ; \mathrm{p}<0.05)$, but not to FRC or $T \mathrm{~L}, \mathrm{CO}$.

\section{Appraisal of self-care agency}

Global ASA was low in COPD patients in the present study, with no clear difference between the high and the low medical consumption group ( $85 \pm 10$ vs $89 \pm 10$; Ns) (table 2).

\section{Determinants of medical consumption}

In single regression analysis, few variables appeared to be related to medical consumption. These included: $P \mathrm{I}$,max, $P$ E,max and QF. Variables related to medical consumption were clearly interrelated (see above). Table 3 summarizes the relationship between variables related to medical consumption and functional variables. Only $P$ E,max and QF were significantly related to medical consumption, whilst a tendency $(\mathrm{p}=0.06)$ was present for PI,max.

In stepwise multiple regression analysis, the only determinant of the variables related to medical consumption in the present study appeared to be QF. QF was a significant determinant of the number of hospital days,
Table 4. - Results of stepwise multiple regression analysis for utilization of health care resources

QF (as \% pred)

\begin{tabular}{ll}
\hline Admissions $\mathrm{n}$ & $0.32^{+}$ \\
Hospital days $\mathrm{n}$ & $0.35^{*}$ \\
Out-patient visits n & $0.37^{*}$ \\
ADD score & $0.36^{*}$ \\
\hline
\end{tabular}

The regression coefficient $(r)$ is the partial $r$ from the multiple regression analysis. No other variables contributed significantly to medical consumption. For definitions see legends to tables 1 and $2 .{ }^{*}: \mathrm{p}<0.05 ;{ }^{+}: \mathrm{p}=0.06$.

the number of out-patient visits, and ADD, whilst a similar tendency was present for the number of admissions $(p=0.06)$. Table 4 summarizes the results of stepwise multiple regression analysis.

\section{Discussion}

The present study clearly demonstrated that: 1) it was possible to identify a group of COPD patients with high and low utilization of health care resources, respectively; 2) pulmonary function, simple walking tests and ASA score were not different between the group of patients with high and those with low medical consumption; 3) ventilatory muscle weakness and, more markedly, peripheral muscle weakness were associated with high medical consumption; 4) peripheral muscle weakness, ADD and medical consumption were interrelated.

At first sight, the present results appear at variance with the studies from Vestbo and Rasmussen [20], and STRAuSS [21]. Both these studies found a relationship between FEV1 and probability and duration of hospital stay in COPD patients. It should be stressed that, unlike the present study, both studies comprise a wide range of patients, even including normal subjects without complaints. The present study represents a much narrower sample of COPD patients, all with an FEV1 approximately $20-40 \%$ pred. In the setting of the present study, with a group of patients who all had similar FEV1, other potential determinants of medical consumption were identified.

Surprisingly, self-care agency did not appear to be related to utilization of health care resources. Several studies have shown that depression is prevalent in COPD patients [22-25]. In addition, although disputed by others [26], several studies found depression to be related to functional status in COPD patients [22-24]. On this 
basis, a relationship between depression and medical consumption might have been expected. The prevalence and severity of depression, however, were not estimated in the present study. The relationship between depression and functional variables, thus, remains to be elucidated.

Several limitations may be present concerning the measures of medical consumption and the ASA score used in the current study. The measures of medical consumption do not provide a direct estimate of the cost of medical care for COPD patients. COPD patients in this study appraised their self-care capabilities as relatively low, both in the high and the low medical consumption group. Mean scores of 85 and 89 were comparable with those of hospitalized patients undergoing coronary bypass surgery [7], or hospitalized psychiatric patients. Healthy elderly individuals living independently at home score clearly better (ASA of about 100). By way of contrast, nursing home patients score below 80 [8]. Patients with low ASA scores tend to use more passive coping strategies (G. Evers, unpublished observations).

Lack of or diminished active participation in decision-making about treatment may explain why capabilities for self-care did not appear to influence decisions about frequency of out-patient visits or frequency and length of hospitalization. Thus, many of these COPD patients appeared to fit well into the classic role of the passive patient. There is evidence, however, that decisions related to hospitalization may be influenced by patients' self care capabilities [8]. The variation in mean ASA scores of subgroups in the latter study was greater than in the present study. Whether or not diminished active participation in decision-making about treatment results from disease severity, patient role expectation from the physician or poor patient-physician communication remains to be elucidated. No relationship could be demonstrated between pulmonary function or muscle force and ASA score, respectively, nor between ASA score and utilization of health care resources. Thus, the results of the present study do not support the concept of disease severity being the most obvious single explanation for utilization of health care resources.

Interestingly, medical consumption appeared to be related to muscle weakness and to steroids taken in the last 6 months. We have previously described relationships between muscle forces and steroids taken in the last 6 months, in COPD patients [9]. The relationship between measures of medical consumption and ADD is not surprising, since steroid treatment is a form of medical consumption. It should be emphasized that the relationships observed are relatively weak, and, therefore, that conclusions must be drawn from the present study with caution. The weak correlations are not surprising in view of the fact that other factors are also likely to determine medical consumption, and that the measurement of muscle strength usually has important interindividual variability $[27,28]$. Psychosocial factors may also be related to the utilization of health care resources.

The relationship between muscle weakness and medical consumption is not readily explained. Several potential mechanistic explanations may be advanced. Firstly, muscle weakness and medical consumption could both be the expression of more severe disease. Although this is certainly a potentially valid explanation, there was no obvious relationship between muscle weakness, medical consumption and severity of disease in the present study. Indeed, FEV1 is usually considered to be a good estimate of severity of disease in COPD patients [29, $30]$. In the present study, FEV1 was the same in the high and low medical consumption group (table 2), and it was not related to medical consumption (table 3 ). Other potential measures of disease severity, such as transfer factor and FRC, were also similar between the two groups. Moreover, no relationship between pulmonary function and ventilatory muscle weakness was present, except for a relationship between TL,CO and $P \mathrm{I}$,max, although FEV1 was related to peripheral muscle force. Nevertheless, the fact that patients in the high medical consumption group frequently had documented exacerbations may be interpreted as more severe disease. In addition, other factors may also determine disease severity in COPD patients, including: blood gas values at rest [31], pulmonary hypertension [32], and exercise capacity [29]. These factors were not measured in the present study.

Secondly, muscle weakness may be associated with enhanced complaints, which then promote admission to hospital. If dyspnoea is a primary reason for hospital admission in COPD patients, then ventilatory muscle weakness may enhance the sensation of dyspnoea [33]. Peripheral muscle weakness may enhance complaints of muscle weakness and fatigue. Although in the present data peripheral muscle weakness seems more tightly linked to medical consumption than ventilatory muscle weakness, similar tendencies are present with ventilatory muscle weakness as well.

Thirdly, ventilatory and peripheral muscle weakness may also be the consequence of medical consumption. Indeed, patients admitted to hospital are more readily treated with corticosteroids, and this treatment may cause muscle weakness in COPD patients [9, 34, 35]. There is no doubt that the relationship between steroid treatment and muscle weakness may be causal. Indeed, numerous animal studies have demonstrated a causal relationship between steroid treatment and muscle weakness [34, 36]. Following this hypothesis, enhanced complaints would lead both to hospital admission and steroid treatment, with consequent muscle weakness. In the present study, a relationship between the utilization of health care resources and steroid treatment was clearly documented. However, the factor that primarily triggers a greater utilization of health care resources remains obscure. Psychosocial variables, such as depression could be primarily related to medical consumption. The relationship between psychosocial function and medical consumption in COPD patients remains to be studied critically. Muscle weakness may also result from a number of other factors, including reduced activity and deconditioning, and long-lasting disease.

The hypotheses formulated above may all be valid, and need testing in well designed prospective studies. Nevertheless, if steroid treatment, muscle weakness and utilization of health care resources were to be related in a causal sequence, it would be of utmost importance to routine management of COPD patients. Indeed, it would then be likely that steroid treatment would be harmful for the average patient, not only causing complaints and muscle weakness, but also enhancing utilization of 
health care resources. In this context, it is significant to note that the benefit of steroid treatment to COPD patients is not always obvious [37-39]. A comprehensive discussion of the usefulness of steroid treatment in COPD patients, however, is clearly beyond the scope of the present paper. The primary triggers of steroid treatment in clinical practice also require critical study.

Conversely, improving functional status and muscle weakness by pulmonary rehabilitation, with special attention to muscle function [40, 41], might be of considerable benefit to COPD patients. Following this reasoning, rehabilitative measures would not only lead to an improved exercise tolerance and improved functional status, but also to reductions in the utilization of health care resources.

Evidence suggesting this effect is available [1]. A prospective randomized trial on the effects of rehabilitation in COPD patients appears necessary to provide a definite answer to this question.

In conclusion, the difference between a group of chronic obstructive pulmonary disease patients with high and low utilization of health care resources appeared to be the presence of muscle weakness in the high medical consumption group. Muscle weakness and steroid treatment correlated with variables related to utilization of health care resources. Whether this relationship is the cause of medical consumption or the consequence of it requires further prospective and well-designed study.

Acknowledgements: The authors thank A. Bisschop for her expert help with data analysis and I. De Geest for her help with data collection.

\section{References}

1. Hodgkin JE. Pulmonary rehabilitation. Clin Chest Med 1990; 11: 447-454.

2. Ley P. In: Communicating with patients: improving communication, satisfaction, and compliance. New York, Chapman and Hall, 1988.

3. Tougaard L, Krone T, Sorknaes A, Ellegaard H. Economic benefits of teaching patients with chronic pulmonary disease about their illness. Lancet 1992; 339: 1517-1520.

4. Ashikaga T, Vacek PM, Lewis PM. Evaluation of a community-based evaluation program for individuals with chronic obstructive pulmonary disease. J Rehabil Res Dev 1980; 46: 23-27.

5. Howland J, Nelson EC, Barlow PB, et al. Chronic obstructive airway disease: impact of health education. Chest 1986; 90: 233-238.

6. Ries AL. In: Guidelines for pulmonary rehabilitation programs. Champaign, USA, Human Kinetics Publishers, 1993.

7. Evers GCM. In: Appraisal of Self-care Agency (ASA) scale. Assen, Maastricht, Van Gorcum, 1989.

8. Evers G, Isenberg M, Philipsen H, Senten M, Brouns G. Validity testing of the Dutch translation of the appraisal of self-care agency (ASA) scale. Int J Nursing Studies 1993; 30: 331-342.

9. Decramer M, Lacquet LM, Fagard R, Rogiers P. Corticosteroids contribute to muscle weakness in chronic airflow obstruction. Am J Respir Crit Care Med 1994; 150: 11-16.

10. American Thoracic Society. Standardization of spirometry: 1987 update. Am J Respir Crit Care Med 1987; 136: $1285-1298$.
11. Quanjer PH, Tammeling GJ, Cotes JE, Pedersen OF, Peslin R, Yernault JC. Lung volumes and forced ventilatory flows. Eur Respir J 1993; 6 (Suppl. 16): 5-40.

12. Ogilvie CM, Forster RE, Blakemore WS, Morton JW. A standardized breathholding technique for the clinical measurement of the diffusing capacity of the lung for carbon monoxide. J Clin Invest 1957; 36: 1-17.

13. Cotes JE, Chinn DJ, Quanjer PH, Roca J, Yernault JC. Standardization of the measurement of transfer factor (diffusing capacity). Eur Respir J 1993; 6 (Suppl. 16): 41-52.

14. Guyatt GH, Pugsley SO, Sullivan MJ, et al. Effect of encouragement on walking test performance. Thorax 1984; 39: 818-822.

15. Mahler DA. Dyspnea: diagnosis and management. Clin Chest Med 1987; 8: 215-230.

16. Borg G. Psychophysical bases of perceived exertion. Med Sci Sports Exerc 1982; 14: 377-381.

17. Black LF, Hyatt RE. Maximal respiratory pressures: normal values and relationship to age and sex. Am Rev Respir Dis 1969; 99: 696-702.

18. Rochester D, Arora NS. Respiratory muscle failure. Med Clin North Am 1983; 67: 573-598.

19. Orem DE. In: Nursing: Concepts of Practice. St. Louis, Mosby, New York McGraw Hill, 1991.

20. Vestbo J, Rasmussen FV. Respiratory symptoms and FEV1 as predictors of hospitalization and medication in the following 12 years due to respiratory disease. Eur Respir J 1989; 2: 710-715.

21. Strauss MJ. Cost and outcome of care for patients with chronic obstructive lung disease. Med Care 1986; 24: 915-924.

22. Agle DP, Baum GL. Psychosocial aspects of chronic obstructive pulmonary disease. Med Clin North Am 1977; 61: 749-758.

23. McSweeny AJ, Grant I, Heaton RK, Adams KM, Timms RM. Life quality of patients with chronic obstructive pulmonary disease. Arch Intern Med 1982; 142: 473478.

24. Labuhn KT, McSweeny AJ. McSweeny AJ, Grant I (eds). Chronic obstructive pulmonary disease: a behavioral perspective. New York, Marcel Dekker, 1994.

25. Grant I, Heaton RK, McSweeny AJ, Adams KM, Timms RM. Neuropsychologic findings in hypoxemic chronic obstructive pulmonary disease. Arch Intern Med 1982; 142: $1470-1476$.

26. Light RW, Merill EJ, Despars JA, Gordon GH, Mutalipassi LR. Prevalence of depression and anxiety in patients with patients with COPD: relationship to functional capacity. Chest 1985; 87: 35-38.

27. Borges O. Isometric and isokinetic knee extension and flexion torque in men and women aged 20-70. Scand $J$ Rehabil Med 1989; 21: 45-53.

28. Stalberg E, Borges O, Ericsson M, et al. The quadriceps femoris muscle in 20-70 year old subjects: relationship between knee extension torque, electrophysiological parameters, and muscle fiber characteristics. Muscle Nerve 1989; 12: 382-389.

29. Anthonisen NR, Wright EC, Hodgkin JE, IPPB Trial Group. Prognosis in chronic obstructive pulmonary disease. Am Rev Respir Dis 1986; 133: 14-20.

30. Burrows B, Bloom JW, Traver GA, Cline MG. The course and prognosis of different forms of chronic airways obstruction in a sample from the general population. N Engl J Med 1987; 317: 1309-1314.

31. Nocturnal oxygen therapy trial group. Continuous or nocturnal oxygen therapy in hypoxemic chronic obstructive 
pulmonary disease: a clinical trial. Ann Intern Med 1980; 93: 391-398.

32. Kawakami Y, Kishi F, Yamamoto H, Miyamoto K. Relation of oxygen delivery, mixed venous oxygenation, and pulmonary hemodynamics to prognosis in chronic obstructive pulmonary disease. N Engl J Med 1983; 308: 1045-1049.

33. Killian KJ, Jones NL. Respiratory muscles and dyspnea. Clin Chest Med 1988; 9: 237-248.

34. Dekhuijzen PNR, Decramer M. Steroid-induced myopathy and its significance to respiratory disease: a known disease rediscovered. Eur Respir J 1992; 5: 997 1003.

35. Decramer M, Stas K. Corticosteroid-induced myopathy involving respiratory muscles in patients with COPD or asthma. Am Rev Respir Dis 1992; 146: 800-802.

36. Dekhuijzen PNR, Gayan-Ramirez G, Dom R, de Bock $\mathrm{V}$, Decramer M. Triamcinolone and prednisolone affect contractile properties and histopathology of rat diaphragm differently. J Clin Invest 1993; 92: 1534-1542.

37. Albert RA, Martin TR, Lewis SW. Controlled clinical trial of methylprednisolone in patients with chronic bronchitis and acute respiratory insufficiency. Ann Intern Med 1980; 92: 753-758.

38. Ziment I. Pharmacologic therapy of obstructive airway disease. Clin Chest Med 1990; 11: 461-486.

39. Stoller JK, Gerborg ZB, Feinstein AR. Corticosteroids in stable chronic obstructive pulmonary disease. J Gen Intern Med 1987; 2: 29-35.

40. Simpson K, Killian K, Mc Cartney N, Stubbing DG, Jones NL. Randomised controlled trial of weight-lifting exercise in patients with chronic air flow limitation. Thorax 1992; 47: 70-75.

41. Siafakas NM, Vermeire P, Pride NB, et al. Optimal assessment and management of chronic obstructive pulmonary disease (COPD). Eur Respir J 1995; 8: 1398-1420. 